\title{
THE BAGHDAD PACT NUCLEAR TRAINING CENTRE
}

\author{
By SiR JOHN COCKCROFT, O.M., K.C.B., C.B.E., F.R.S.
}

$\mathrm{T}$ HE Baghdad Pact Nuclear 'Training Centre was formally opened by H.M. King Feisal II on March 31 in the presence of Ambassadors, Ministers and members of the Scientific Council of the Centre. The Centre has been founded by the Pact countries, Britain, Iraq, Iran, Pakistan and Turkey, to provide training in radioisotope techniques for scientists from the Pact countries and possibly other countries in the region. The laboratory has been provided by the Government of Iraq and was intended originally for date research. It is a pleasant building on two floors, adequately equipped for its purpose, with some of which might be more specialized. For example, a course on the application of radioisotopes to medicine is contemplated. For this purpose the training staff would be strengthened by specialists from the United Kingdom.

It is intended that the Centre should promote the application of radioisotopes and atomic energy in the region by collaborating with existing laboratories and research groups.

A start will at once be made to collaborate with medical centres on the introduction of radioisotopes for diagnostic and therapeutic work. Other studies

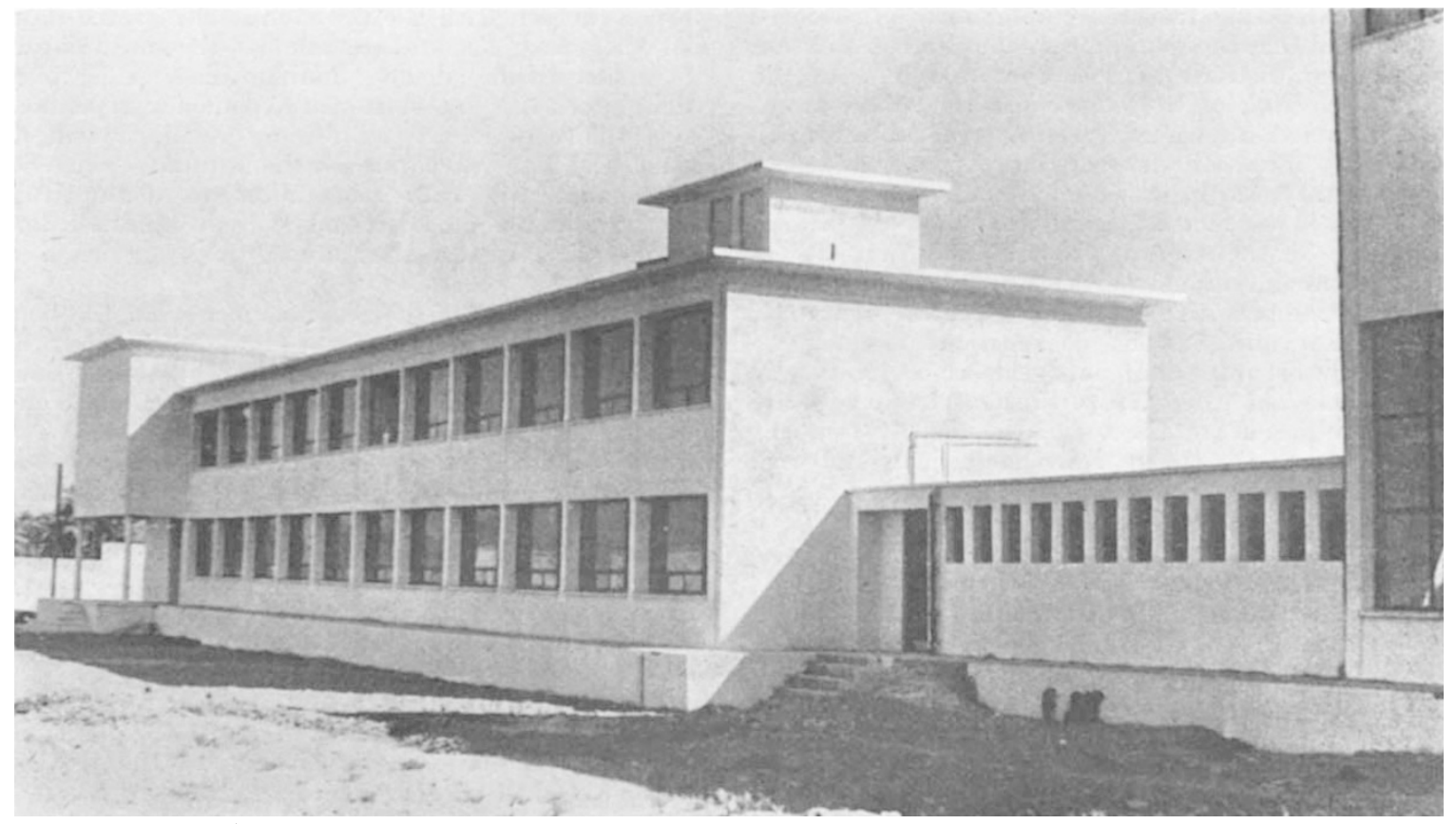

[Central Office of Information: Crown copyright reserved

Fig. 1. The Baghdad Pact Nuclear Centre in the district of Salchiyah in Baghdad

laboratories, lecture room, library and staff offices. The first technical director, Mr. W. J. Whitehouse, together with four other staff, have been seconded to the Centre by the Atomic Energy Authority in Britain. Eight staff from the Pact countries were trained at Harwell during 1956 and are now at their posts. The staff now cover the following fields: nuclear physics; radiochemistry; electronics; medical applications; and agriculture.

The equipment has been supplied by the United Kingdom, largely through Harwell, and consists of standard equipment of a radioisotope school adequate for twenty students together with the necessary supply of radioactive isotopes, text-books and reports. All member countries are contributing to the running expenses.

The first course for twenty students started in mid-April and will be similar in content and length to the Harwell Isotope School course. The present intention is to have three or four courses a year, will be made in connexion with the oil industry and agriculture, and water conservation and control.

The Baghdad Museum, which has an extremely interesting collection of antiquities, is interested in obtaining help in establishing the carbon-14 dating method. The electronic specialists of the Centre may be able to help.

The application of nuclear power will not be worthwhile in Iraq and Turkey in the foreseeable future, owing to the abundant supply of oil and hydro power. Iran and Pakistan are, however, interested in the potentialities of nuclear power units of medium output for some areas, and the Centre will help by advice to promote this development.

The foundation of the Centre is an experiment in introducing the new techniques of radioisotopes to an important group of Middle East countries. Britain's role is to help by advice and by the provision of a fow key staff. 